\title{
Article
}

\section{Influence of Sweat on Joint and Sensor Reliability of E-Textiles}

\author{
Martin Hirman*(D), Jiri Navratil (D), Michaela Radouchova, Jiri Stulik and Radek Soukup \\ Department of Materials and Technology, Faculty of Electrical Engineering, University of West Bohemia, \\ 30100 Pilsen, Czech Republic; jirkanav@fel.zcu.cz (J.N.); mradouch@fel.zcu.cz (M.R.); stulikj@fel.zcu.cz (J.S.); \\ rsoukup@fel.zcu.cz (R.S.) \\ * Correspondence: hirmanm@fel.zcu.cz
}

Citation: Hirman, M.; Navratil, J.; Radouchova, M.; Stulik, J.; Soukup, R. Influence of Sweat on Joint and Sensor Reliability of E-Textiles. Energies 2022, 15, 506. https:// doi.org/10.3390/en15020506

Academic Editor: Saverio Latorrata

Received: 14 December 2021

Accepted: 7 January 2022

Published: 11 January 2022

Publisher's Note: MDPI stays neutral with regard to jurisdictional claims in published maps and institutional affiliations.

Copyright: (c) 2022 by the authors. Licensee MDPI, Basel, Switzerland. This article is an open access article distributed under the terms and conditions of the Creative Commons Attribution (CC BY) license (https:// creativecommons.org/licenses/by/ $4.0 /)$.

\begin{abstract}
This article addresses reliability under the sweat of interconnection techniques for the mounting surface mounted device (SMD) components and fully printed humidity sensors onto conductive stretchable textile ribbons. Samples underwent testing for the effect of ageing by artificial sweat on their electrical resistance using both alkaline and acidic artificial sweat. The best results in terms of electrical resistance change were obtained for samples soldered to the conductive fibers interwoven in the ribbon. However, this method can damage the ribbon due to the high temperature during soldering and significantly reduce the mechanical properties and flexibility of the ribbon, which can lead to a limited service life of samples. On the other hand, adhesive bonding is a very interesting alternative, where the above-mentioned properties are preserved, but there is a significant effect of sweat ageing on electrical resistance. The results of fully printed graphene-based humidity sensors show that, for the intended use of these sensors (i.e., detection of changes in moisture on the human body), usage of the samples is possible, and the samples are sufficiently reliable in the case of sweat degradation. In addition, the response of the sensor to humidity is quite high: $98 \%$ at a relative humidity of $98 \%$.
\end{abstract}

Keywords: e-textiles; conductive stretchable textile ribbon; nonconductive adhesive compression bonding; soldering onto textile; fully printed graphene-based humidity sensor

\section{Introduction}

At present, the popularity of electronic textiles (e-textiles) as a class of smart textiles is growing according to the wide range of potential applications, such as in the healthcare, sports, fitness, fashion, telecommunications, automotive and aerospace industries [1,2]. A combination of textile-based circuits and conventional passive components, or fully printed passive sensors, seems to be a reasonable solution for designing the smart textiles used in many novel applications, such as safety elements, healthcare or well-being products, and sport garments [3-5]. One of the important questions is whether surface-mounted device (SMD) components can be attached to textile-based substrates with properties (especially reliability) comparable to those of standard rigid fiberglass-reinforced boards (PCBs) with attached components. The greatest difference between smart textiles and common wearable electronics is that the sweat from any activity is absorbed by the textile substrate, and this process can affect the electrical parameters. For hygienic reasons, the textile also sometimes needs to be washed, which could also affect the joint properties [6]. Moreover, consumers expect e-textiles to retain the features of normal clothes, such as wearing comfort, elasticity, washability, breathability, and the use of hypoallergic materials that are nonirritating for skin, while providing added value functions such as heating, active illumination, and environmental or body parameter monitoring. This is a major challenge as all these aspects must be taken into consideration in e-textile design [7-9].

One of the possible materials for smart textile use is electrically conductive textile ribbons. These ribbons are flexible and stretchable, and the electrically conductive contact of an SMD component can be made with a conductive track woven in the ribbon, which 
was proven in our previous experiments [10,11]. The disadvantage of these ribbons is a low resistance to higher temperatures. The standard connection method on rigid printed circuit boards (fiberglass-reinforced epoxy substrates) is soldering or, alternatively, using electrically conductive adhesives. As mentioned, for textile substrates, the higher temperature used for the standard soldering process can be a problem. However, low-temperature soldering, while maintaining an acceptable temperature and a short soldering process time, is possible $[12,13]$. Alternatively, adhesive bonding with an electrically conductive adhesive (ECA) can be employed. The disadvantage of this process is the long curing time, and another process step is necessary for encapsulation. Another possibility is adhesive bonding with a nonconductive adhesive (NCA) to fix the components onto the substrate, and a conductive joint made by the direct contact of a component with a substrate is possible [14] The problem with thermosetting adhesives is their long curing times, but a UV-curable adhesive with almost instant curing can be used. For the use of soldering while maintaining a low temperature [15], an ECA [16] or an NCA seems to be the easiest and cheapest way for contacting nearly all types of SMD components to a textile while maintaining the wearing comfort and good reliability [17]. The soldering and ECA techniques create electrical contact between components and conductive threads via solder or conductive particles in the adhesive. The NCA contact technique creates direct contact between conductive threads and the component pad (by using mechanical pressure), and the adhesive is only used for fixing this mechanical contact [14]. UV light curing is possible for an NCA. It can provide a high-speed, low-temperature, inexpensive, and highly automation-friendly contact process for creating smart textiles.

The greatest challenge is the reliability of each connection method in various environments where the product is expected to be used. As mentioned above, wearable textiles have to withstand various conditions that are caused by many factors. One of them is sweat, which might be a significant factor, e.g., for smart textile sports garments. Thus, the reliability testing of joints between SMD chip resistors adhesive bonded or soldered onto textile ribbons during accelerated aging by artificial sweat is important. Moreover, reliability testing of fully printed encapsulated sensors on textile ribbons during sweat aging is also important.

The two basic factors characterizing the environment are temperature and relative humidity. In recent years, graphene-based sensors of these two quantities were developed. The reasons for using graphene are its unique properties, which include high electrical and thermal conductivity, high mechanical resistance and material flexibility, and the possibility of wide modifications to the graphene surface $[18,19]$. These properties make graphene suitable for use in flexible and wearable sensors [20]. In addition, these sensors can be prepared in a printed form [21].

\section{Materials and Methods}

For the experiment, three types of samples were used. The first sample type was a ribbon with ten chip resistors connected by soldering and encapsulated by an NCA. The second sample type was a ribbon with ten chip resistors connected by an adhesive bonding technique with an NCA and encapsulated by the same NCA. The third sample type was ribbons with a humidity sensor fully printed by graphene paste through a stencil and partially encapsulated by an NCA. The details of the sample labels can be seen in Table 1.

Before the conducting of our experiment, a few hypotheses were made. The first hypothesis was that the electrical resistance of the bonded or soldered adhesive joint between the SMD component metallization and conductive track woven in the ribbons will be reliable during accelerated aging by artificial sweat. The second hypothesis was that stretching of the ribbon at $150 \%$ of its relaxed length during the soldering or adhesive bonding process could slightly improve the sample reliability during aging because the internal tension of the ribbon around the joint is different, and the penetration of sweat into the joint may vary. The third hypothesis was that fully printed and partially encapsulated humidity sensors on the ribbons would be reliable during accelerated aging by artificial sweat. 
Table 1. Table of used sample types and sample labels.

\begin{tabular}{|c|c|c|c|c|c|c|c|c|}
\hline \multirow{2}{*}{$\begin{array}{c}\text { Sample type } \\
\text { Sample marking }\end{array}$} & \multicolumn{4}{|c|}{ 1-Soldered resistors } & \multicolumn{4}{|c|}{ 2-NCA bonded resistors } \\
\hline & $1 \mathrm{~A}$ & $1 \mathrm{~B}$ & $1 \mathrm{C}$ & $1 \mathrm{D}$ & $2 \mathrm{~A}$ & $2 \mathrm{~B}$ & $2 \mathrm{C}$ & $2 \mathrm{D}$ \\
\hline Material used & \multicolumn{4}{|c|}{ SnBi solder paste } & \multicolumn{4}{|c|}{ UV-curable acrylic-based adhesive (NCA) } \\
\hline Stretching & $\begin{array}{c}\text { No } \\
(100 \%)\end{array}$ & $\begin{array}{c}\text { Yes } \\
(150 \%)\end{array}$ & $\begin{array}{c}\text { No } \\
(100 \%)\end{array}$ & $\begin{array}{c}\text { Yes } \\
(150 \%)\end{array}$ & $\begin{array}{c}\text { No } \\
(100 \%)\end{array}$ & Yes $(150 \%)$ & $\begin{array}{c}\text { No } \\
(100 \%)\end{array}$ & $\begin{array}{c}\text { Yes } \\
(150 \%)\end{array}$ \\
\hline Sweat type & Alkaline & Alkaline & Acidic & Acidic & Alkaline & Alkaline & Acidic & Acidic \\
\hline Sample type & \multicolumn{8}{|c|}{ 3-Graphene sensors } \\
\hline Sample marking & $3 \mathrm{~A}$ & $3 \mathrm{~B}$ & $3 C$ & $3 \mathrm{D}$ & $3 \mathrm{E}$ & $3 \mathrm{~F}$ & $3 G$ & $3 \mathrm{H}$ \\
\hline Material used & \multicolumn{2}{|c|}{ G-square $3 \times 3$} & \multicolumn{2}{|c|}{$\mathrm{T}$-square $3 \times 3$} & \multicolumn{2}{|c|}{ G-rectangle $1 \times 3$} & \multicolumn{2}{|c|}{$\mathrm{T}$-rectangle $1 \times 3$} \\
\hline Stretching & \multicolumn{8}{|c|}{ No $(100 \%)$} \\
\hline Sweat type & Alkaline & Acidic & Alkaline & Acidic & Alkaline & Acidic & Alkaline & Acidic \\
\hline
\end{tabular}

\subsection{Electrically Conductive Textile Ribbons}

In the experiment, specially developed electrically conductive textile stretchable ribbons were used. These ribbons are protected by patent No. 308614 "Conductive elastic woven fabric, in particular conductive elastic woven ribbon". These ribbons consist of polyester threads in a warp and weft (strength and durability), rubber threads in a warp (stretchability), and special hybrid conductive threads in a warp (electrical conductivity along the ribbon). The hybrid conductive threads consist of continuous PES monofilaments and eight silver-plated copper conductive microwires for each thread. The ribbon is woven in a stretched state; thus, the ribbon shrinks after its production, and the hybrid yarns inside are naturally arranged in the shape of a horseshoe. This allows the ribbon to be repeatedly stretched by up to $170 \%$ of its relaxed length without damage. A schematic cross-section of the ribbon is shown in Figure 1.

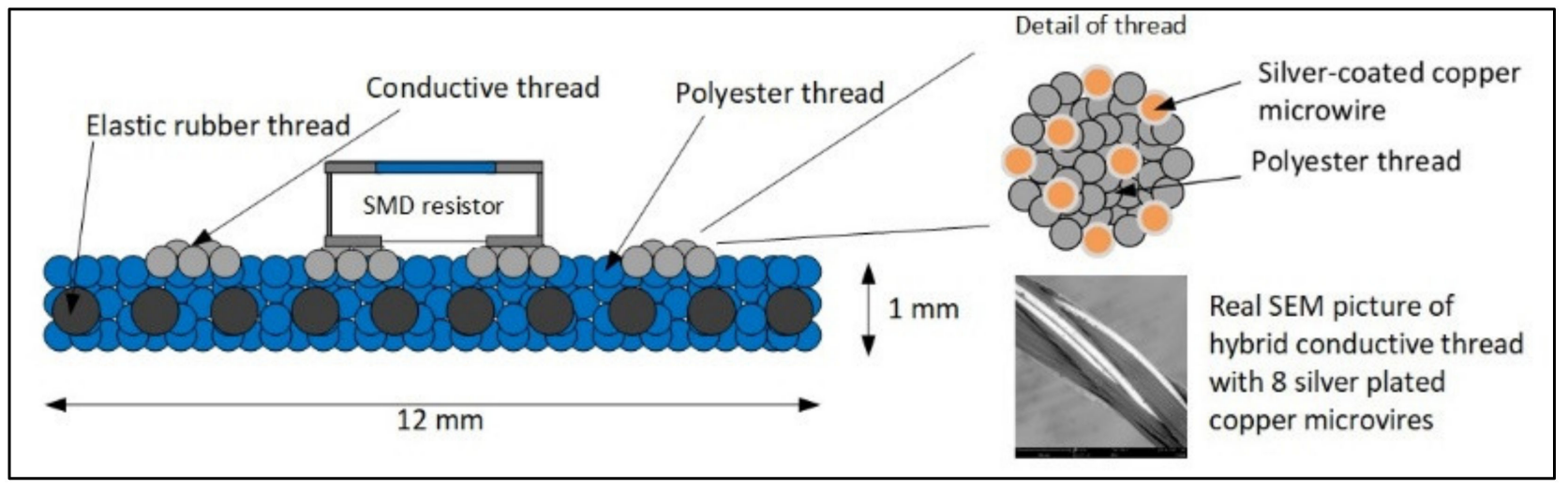

Figure 1. Schematic cross-section of the conductive textile ribbon used in the experiment.

The ribbon has four conductive traces woven inside with a spacing of $2.54 \mathrm{~mm}$, which is the standard spacing for the electronic industry. Each trace has an electrical resistivity in the range of ohms per meter ribbon length and consists of five hybrid conductive threads (i.e., 40 conductive microwires for each trace). This resistance is sufficient for most e-textile applications. The pros of these ribbons are accessibility of conductive traces from the surface and good solderability of the microwires used in the hybrid threads, compared to the silver metallized polyamide threads commonly used in standard conductive ribbons. The traces in the ribbon for the first and second sample types were interrupted every three centimeters by hundreds of amps. Electric discharge was generated by a resistance spot welder from the Sunstone company (see Figure 2) to enable individual electrical resistance measurement of each component by the four-point probe sensing method. 


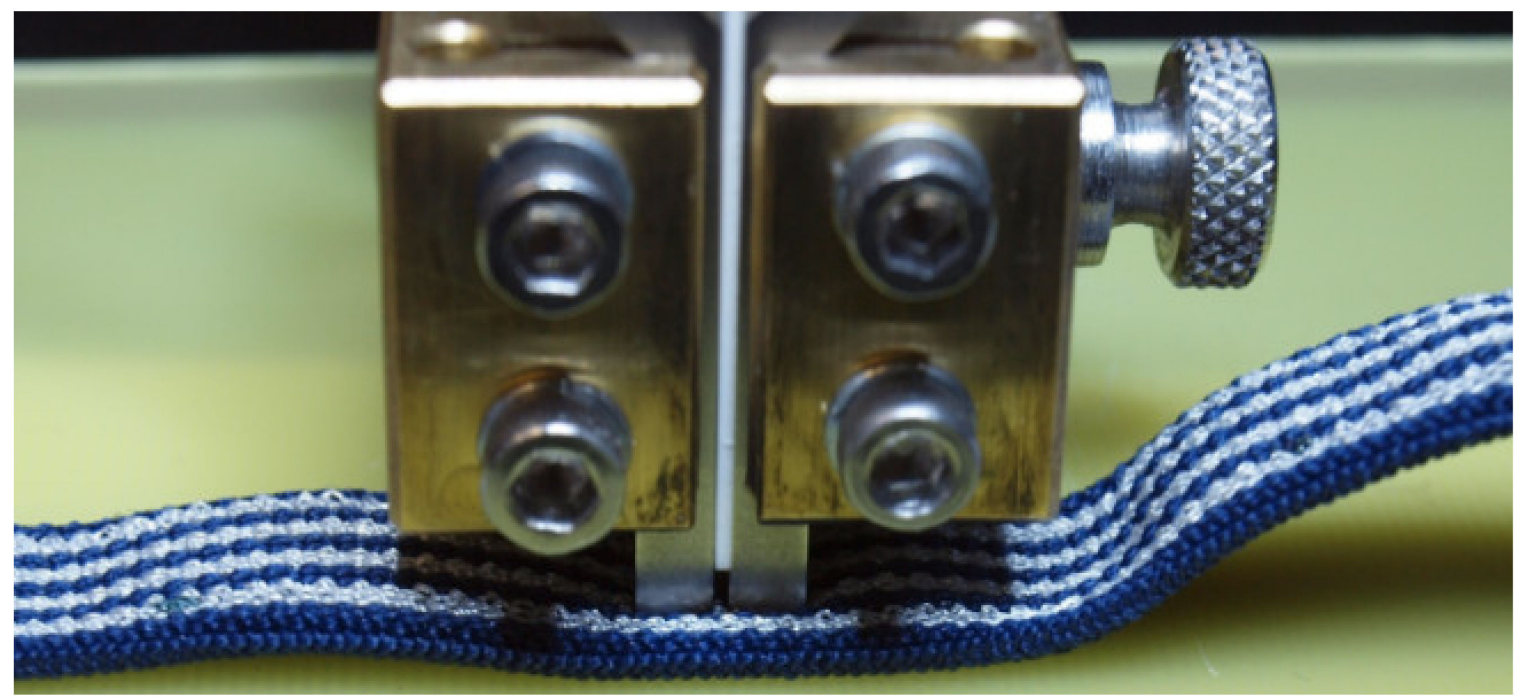

Figure 2. Details of trace interruption by electric discharge.

\subsection{First Sample Type-Soldering $(1 A, 1 B, 1 C, 1 D)$}

Ten SMD chip resistors of type 1206 with zero ohm resistance were used for each ribbon for the first sample type. These resistors were soldered perpendicular to the ribbon traces, and the resistors perfectly fit the spacing of the ribbon conductive traces. Lowtemperature tin-bismuth solder paste with a melting point of $139^{\circ} \mathrm{C}$ was used for soldering chip resistors onto the ribbon traces. The composition of this paste is $40-50 \%$ tin, $4.5-6.5 \%$ rosin (ROL0), and 50-60\% bismuth [22]. The soldered sample production procedure was as follows. The solder paste was applied onto the two central traces by dispensing. After that, the resistor was mounted onto the paste and gently pushed by tweezers into the traces. Then, hand soldering by hot air was carried out. Finally, each soldered resistor was encapsulated by a nonconductive UV curable adhesive to ensure higher chemical resistance and better mechanical properties. One part of the soldered samples was soldered and encapsulated in the stretched state (i.e., the ribbons were stretched to $150 \%$ of their relaxed length and fixed in this stretched position for the whole manufacturing process).

\subsection{Second Sample Type-Adhesive Bonding $(2 A, 2 B, 2 C, 2 D)$}

For the second sample type, the same type and positions of chip resistors as the first sample type were used. An electrically nonconductive, UV-curable, acrylic-based adhesive (NCA) was used for the mechanical connection of chip resistors onto the ribbons. The composition of the adhesive is $30-60 \%$ isobornyl acrylate; $10-30 \% \mathrm{~N}, \mathrm{~N}$-dimethylacrylamide; $1-10 \%$ [3-(2,3-epoxypropoxy)propyl] trimethoxysilane; $1-5 \%$ gamma-glycidoxypropyl trimethoxysilane; $1-5 \%$ silica, amorphous, fumed, crystal-free; $1-5 \%$ diphenyl-2,4,6trimethylbenzoyl phosphine oxide; and 0.1-1\% 2-hydroxyethyl acrylate. This adhesive has the ability to fluoresce and a wide operating temperature range $\left(-40{ }^{\circ} \mathrm{C}\right.$ to $\left.+150^{\circ} \mathrm{C}\right)$ [23] The adhesive bonded sample production procedure was as follows. The adhesive was applied onto the ribbon between two central traces by pin transfer. After that, the resistor was mounted to the adhesive and mechanically pushed by a thorn into the conductive traces in the ribbon with a downforce of $30 \mathrm{~N}$. The pressure caused adhesive extrusion from the space between the resistor pads and conductive traces on the ribbon. The adhesive reached a pointwise zero thickness, allowing intimate contact between the metal parts. The resistor pads were also pressed into the conductive traces, and direct mechanical-electrical contact was made; see the X-ray-computed tomography pictures in Figure 3. Then, the adhesive, still under pressure, was cured by UV light for mechanical fixation of the direct contact. The whole principle of this adhesive bonding technique is shown in Figure 4. Finally, each adhesive-bonded resistor was encapsulated by the same adhesive to ensure higher chemical resistance and better mechanical properties. One part of the adhesive- 
bonded samples was bonded and encapsulated in the stretched state (i.e., the ribbons were stretched to $150 \%$ of their relaxed length and fixed in this stretched position for the whole manufacturing process).
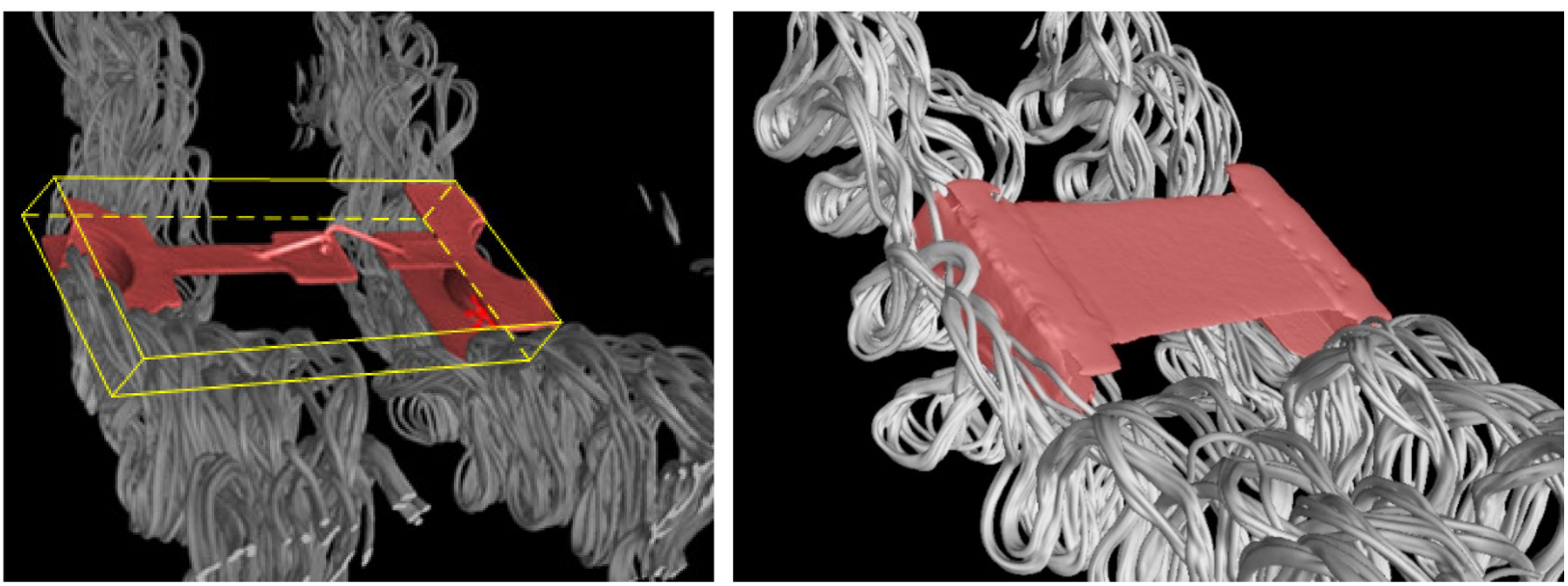

Figure 3. Examples of SMD chip components connected by an NCA onto a conductive ribbon.

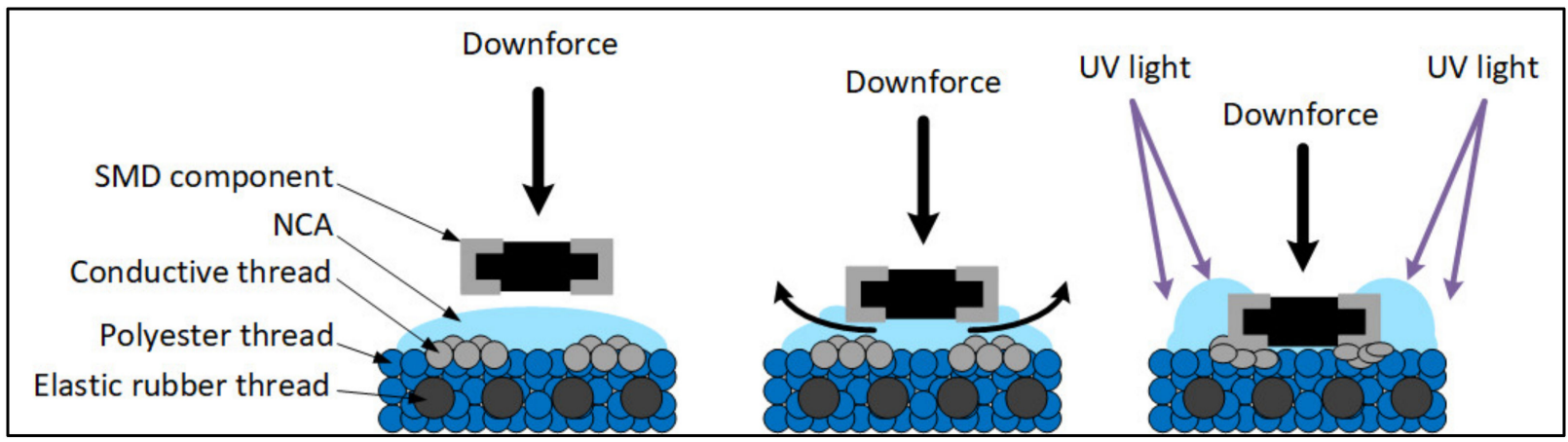

Figure 4. Principle of electrical connection of the SMD resistor to the ribbon by the NCA bonding technique.

\subsection{Third Sample Type-Humidity Graphene Sensors (3A, 3B, 3C, 3D, 3E, 3F, 3G, 3H)}

For the third sample type, two different graphene-based, screen-printing pastes were used to prepare humidity sensors. Both pastes were purchased from Sun Chemicals ${ }^{\circledR}$ and differed in their solid content and sheet resistivity. The first paste, marked G, is type C2131121D3 with a solid content of $41 \%$ and a sheet resistance of $10 \mathrm{ohms} / \mathrm{sq}$ at a $25 \mu \mathrm{m}$ layer thickness. The second paste, type C2171023D1, designated T, has a solid content of $35 \%$ and a sheet resistance of $7.5 \mathrm{ohms} / \mathrm{sq}$ at a layer thickness of $25 \mu \mathrm{m}$.

These graphene pastes were applied onto the ribbon between two central traces by stencil printing. The dimensions of the deposited paste were $3 \mathrm{~mm} \times 3 \mathrm{~mm} \times 0.12 \mathrm{~mm}$ and $1 \mathrm{~mm} \times 3 \mathrm{~mm} \times 0.12 \mathrm{~mm}$. After that, the samples were dried in a laboratory drying oven at $60{ }^{\circ} \mathrm{C}$ for $60 \mathrm{~min}$. Finally, each sensor was partially encapsulated by the same adhesive to ensure higher chemical resistance and better mechanical properties. After encapsulation, final drying of the sample was conducted in a laboratory drying oven at $60{ }^{\circ} \mathrm{C}$ for $60 \mathrm{~min}$.

\subsection{Electrical Resistance Measurement}

The electrical resistance of each sample was measured by a Keithley 2701 device by the four-wire sensing method of resistance measurement in a defined environment: temperature of $25^{\circ} \mathrm{C}$ and relative humidity (RH) of approximately $50 \%$. 


\subsection{Sweat Aging}

In practice, there are two types of human sweat: alkaline and acidic, which depend on the type of human skin. In our experiment, artificial sweat for both sweat types was prepared according to the international standard ISO105-E04 [24]. The compositions of the sweats can be seen in Table 2 .

Table 2. Table of artificial sweat composition.

\begin{tabular}{|c|c|c|}
\hline \multirow[t]{2}{*}{ Chemical Composition (Formula) } & $\begin{array}{l}\text { Alkaline Solution } \\
\mathrm{pH}=8.0\end{array}$ & $\begin{array}{l}\text { Acidic Solution } \\
\mathrm{pH}=5.5\end{array}$ \\
\hline & Amount & Amount \\
\hline L-histidine monohydrochloride monohydrate $\left(\mathrm{C}_{6} \mathrm{H}_{9} \mathrm{O}_{2} \mathrm{~N}_{3} \cdot \mathrm{HCl} \cdot \mathrm{H}_{2} \mathrm{O}\right)$ & $0.5 \mathrm{~g}$ & $0.5 \mathrm{~g}$ \\
\hline Sodium chloride $(\mathrm{NaCl})$ & $5 \mathrm{~g}$ & $5 \mathrm{~g}$ \\
\hline \multirow{2}{*}{$\begin{array}{l}\text { Disodium hydrogen orthophosphate dodecahydrate }\left(\mathrm{Na}_{2} \mathrm{HPO}_{4} \cdot 12 \mathrm{H}_{2} \mathrm{O}\right) \\
\text { or Disodium hydrogen orthophosphate dihydrate }\left(\mathrm{Na}_{2} \mathrm{HPO}_{4} \cdot 2 \mathrm{H}_{2} \mathrm{O}\right)\end{array}$} & $5 \mathrm{~g}$ & - \\
\hline & $2.5 \mathrm{~g}$ & $2.2 \mathrm{~g}$ \\
\hline Total volume & $1000 \mathrm{~mL}$ & $1000 \mathrm{~mL}$ \\
\hline
\end{tabular}

Accelerated aging was designed and realized in three stages with the same procedures and different time steps; the details are shown in Table 3 and Figure 5.

Table 3. Table of the resulting experimental aging times.

\begin{tabular}{ccccccccccccc}
\hline \multicolumn{10}{c}{} & \multicolumn{1}{c}{ Legend } \\
\hline Cycles min Sweat & $\mathbf{1}$ & $\mathbf{2}$ & $\mathbf{3}$ & $\mathbf{4}$ & $\mathbf{5}$ & $\mathbf{6}$ & $\mathbf{7}$ & $\mathbf{8}$ & $\mathbf{9}$ & $\mathbf{1 0}$ & $\mathbf{1 1}$ & $\mathbf{1 2}$ \\
\hline Cverall hours in sweat & 0.5 & 1 & 1.5 & 2 & 2.5 & 3 & 3.5 & 4 & 4.5 & 5 & 5.5 & 6 \\
\hline Overall hours in water & 0.5 & 1 & 1.5 & 2 & 2.5 & 3 & 3.5 & 4 & 4.5 & 5 & 5.5 & 6 \\
\hline Days in liquid & 0.04 & 0.08 & 0.13 & 0.17 & 0.21 & 0.25 & 0.29 & 0.33 & 0.38 & 0.42 & 0.46 & 0.5 \\
\hline Cycles & $\mathbf{1 3}$ & $\mathbf{1 4}$ & $\mathbf{1 5}$ & $\mathbf{1 6}$ & $\mathbf{1 7}$ & $\mathbf{1 8}$ & $\mathbf{1 9}$ & $\mathbf{2 0}$ & $\mathbf{2 1}$ & $\mathbf{2 2}$ & $\mathbf{2 3}$ & $\mathbf{2 4}$ \\
\hline Overall hours in sweat & 6.5 & 7 & 31 & 55 & 79 & 103 & 127 & 151 & 319 & 487 & 655 & 823 \\
\hline Overall hours in water & 6.5 & 7 & 7.5 & 8 & 8.5 & 9 & 9.5 & 10 & 11 & 11 & 12 & 12 \\
\hline Days in liquid & 0.54 & 0.58 & 1.6 & 2.6 & 3.6 & 4.7 & 5.7 & 6.7 & 13.7 & 20.8 & 27.8 & 34.8 \\
\hline
\end{tabular}

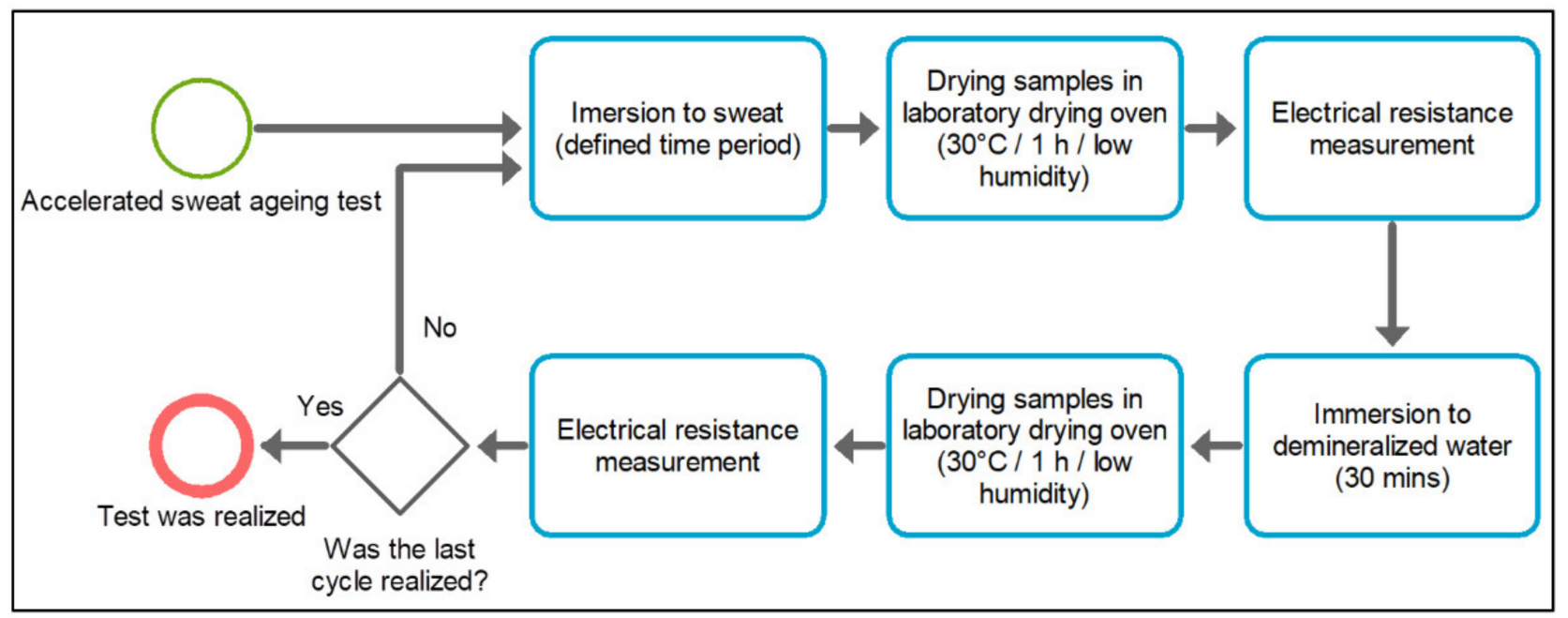

Figure 5. Procedure of conducting accelerated aging by artificial sweat test. 


\section{Results and Discussion}

\subsection{Conductive Joint Samples}

The measured values were statistically analyzed, and boxplot diagrams were prepared (see Figures 6 and 7). The results show that the electrical resistance of joints for soldered samples during aging by sweat is low and stable for both sweat types without significant differences between sample types. The results of the adhesive-bonded samples show that the electrical resistance grows during aging and that the deviation of samples increases. In the diagrams, small differences in the boxplots of new adhesive-bonded samples are observed. Our manufacturing is an experimental prototype production conducted by hand (not automated), and the placement of the thorn onto the component can be slightly different for each sample, which can lead to the production of a lower-quality sample. Such a sample can be degraded faster, which causes greater differences after aging. This problem can be eliminated by preparing a large number of samples, but this was not possible because the preparation of samples is expensive and time-consuming. We solved this problem by preparing a line chart with the median of values (see Figure 8 ). In the case of median values, the outliers are suppressed. This chart shows that adhesive-bonded samples have a higher electrical resistance after their production and that the electrical resistance of adhesive-bonded samples grows during the first few hours in sweat; however, after this initial growth, the values are relatively stable, with only a slight increase over time. The results also show that samples under alkaline sweat have a slightly worse resistance, but this difference is relatively insignificant.

The samples after the whole aging process (i.e., $823 \mathrm{~h}$ in sweat) were submitted for microscopic observation to find visual changes (see Figures 9 and 10). The degradation of the sample is clearly visible; however, encapsulation clearly fulfilled its purpose, and the joint under encapsulation was protected against humidity and sweat. As can be seen, the residues are not verdigris from copper wires, but only pigments transferred from blue polyester threads to the transparent polyester threads inside the hybrid conductive threads.

Metallographic cross-sections of ribbon traces after artificial sweat aging were prepared and observed by an Olympus LEXT OLS 5000 confocal laser scanning microscope (see Figure 11). The observation shows that transparent polyester threads were slightly colored. The details of electrically conductive microwires show that some of these wires are degraded under the silver coating, but our experiment was much more challenging than the standard usage of smart textiles.

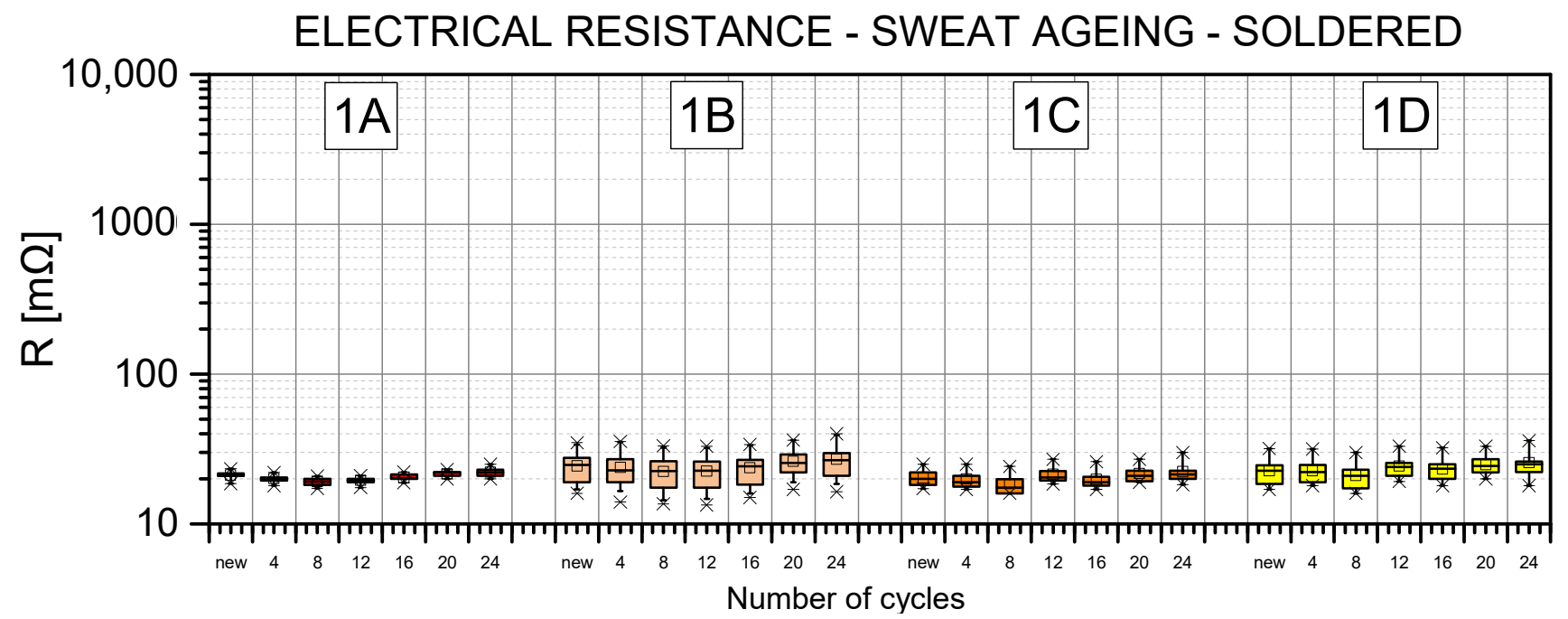

Figure 6. Boxplot diagram of soldered joint (first sample type) electrical resistance for samples 1A, $1 \mathrm{~B}, 1 \mathrm{C}$ and $1 \mathrm{D}$. 


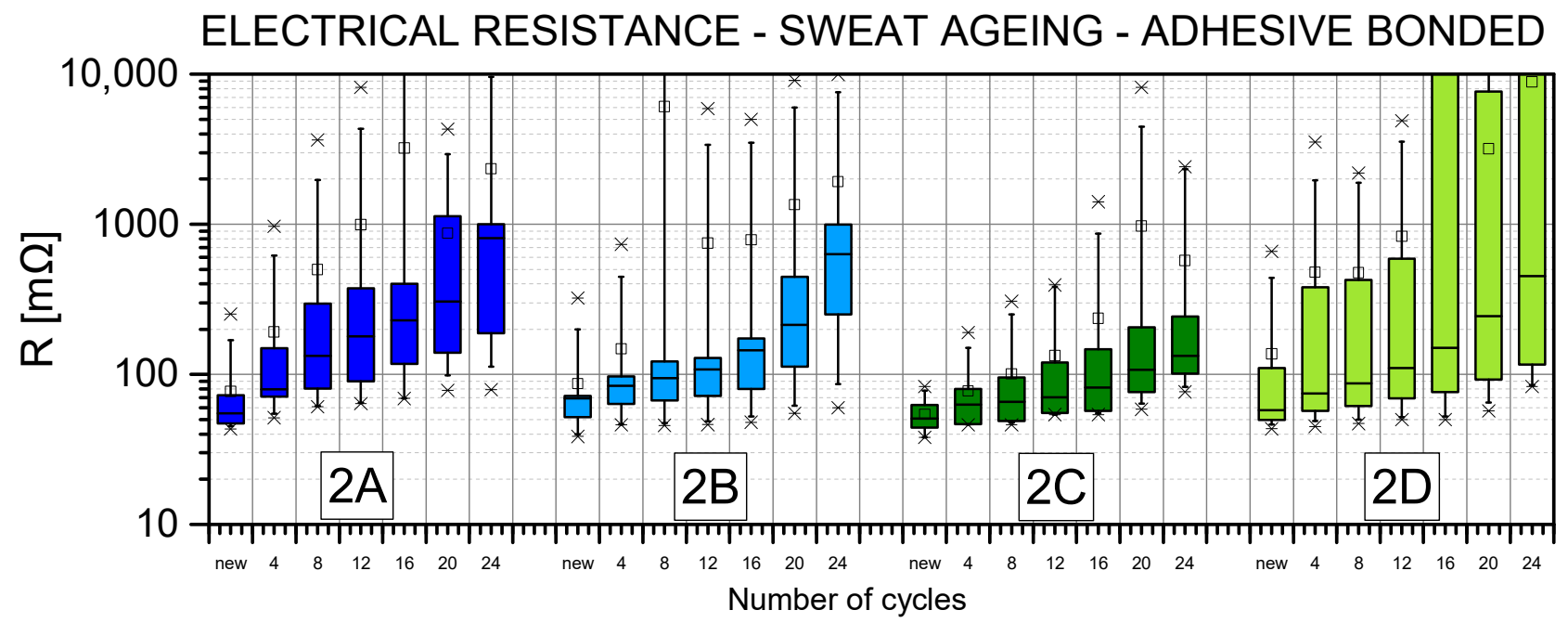

Figure 7. Boxplot diagram of adhesive-bonded joint (second sample type) electrical resistance for samples 2A, 2B, 2C and 2D.

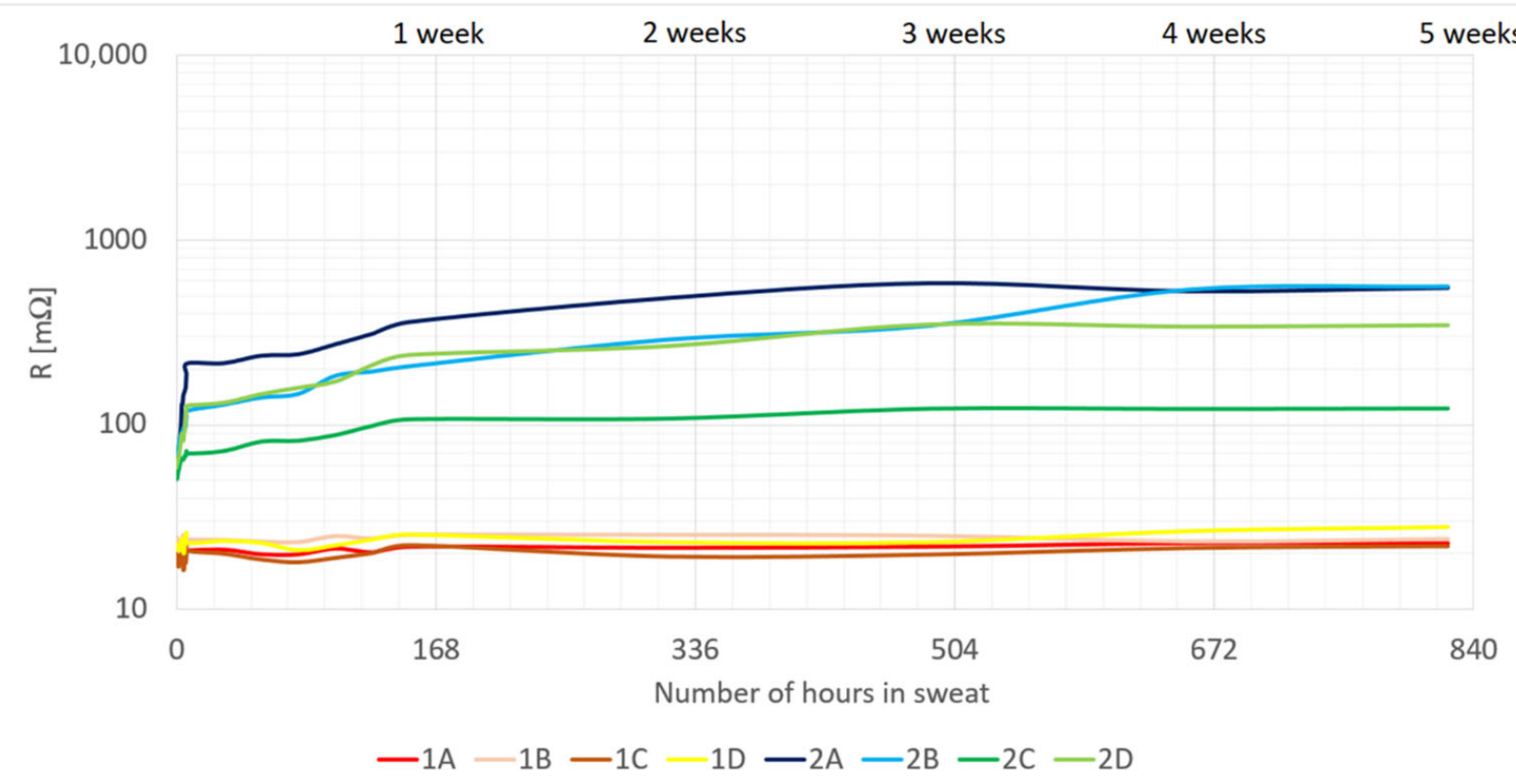

Figure 8. Medians of electrical resistance for the first (1A, 1B, 1C, 1D) and second (2A, 2B, 2C, 2D) sample types tested under sweat.

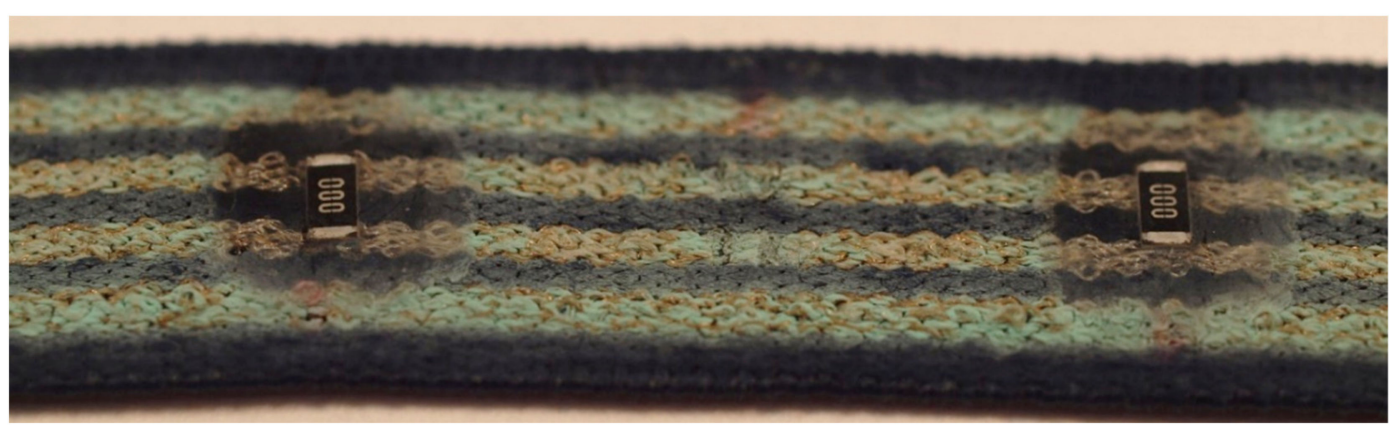

Figure 9. Example of a soldered sample after aging by artificial sweat. 

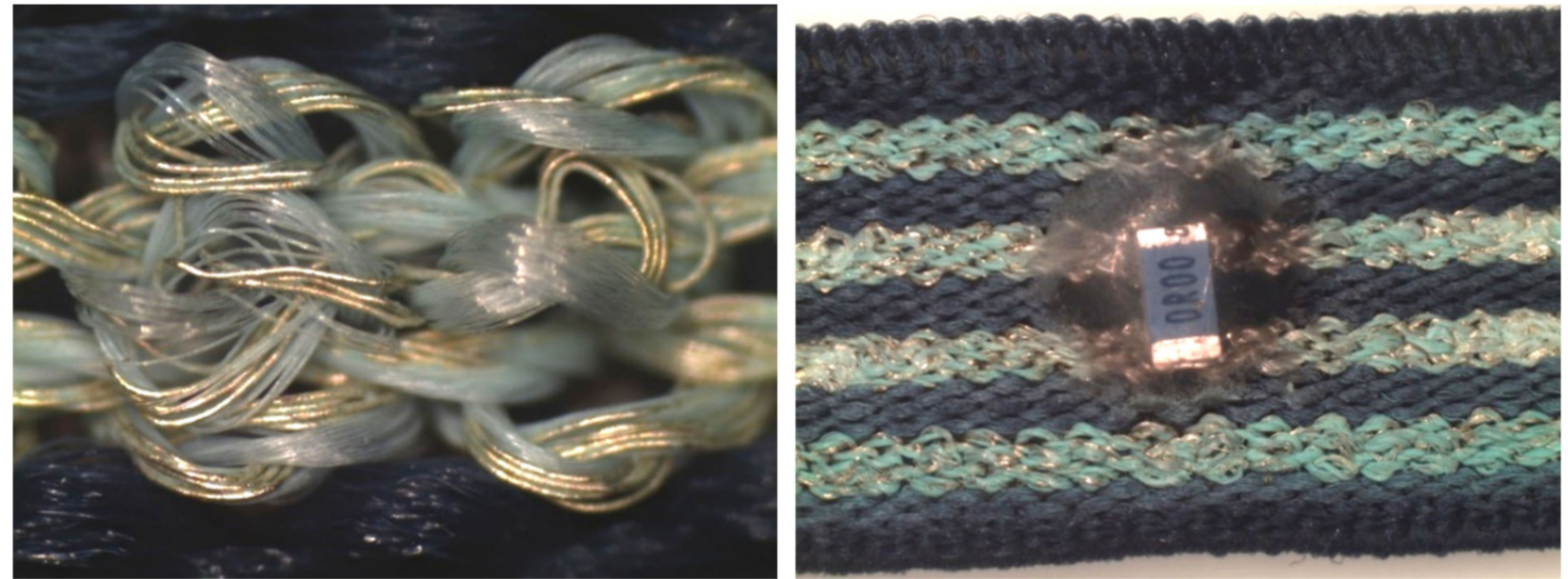

Figure 10. Details of the sample after aging by artificial sweat.
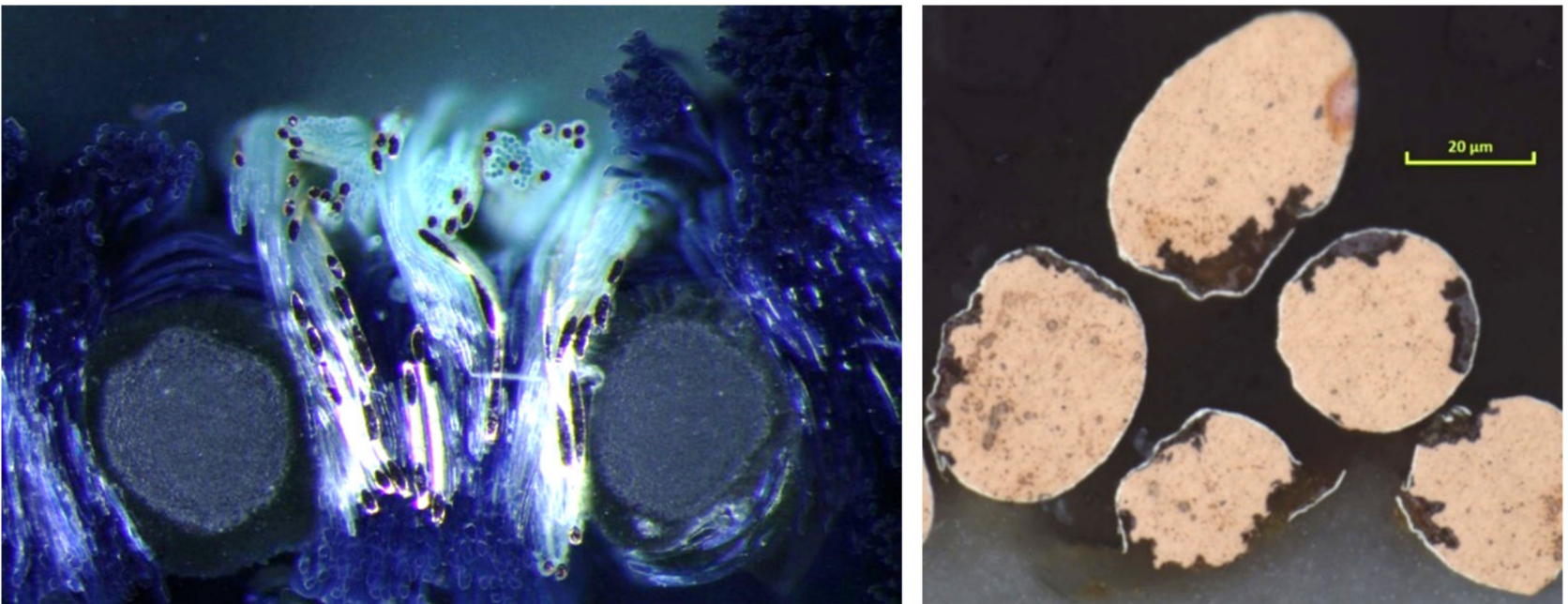

Figure 11. Microscopic observation of metallographic cross-sections of ribbon traces after artificial sweat aging.

\subsection{Humidity Sensor Samples}

Graphene occurs in the paste in the form of small multilayer flakes. These flakes contain defects in their structure (mainly at the edges), where oxygen groups such as carboxyl, hydroxyl and epoxy groups are most often attached. There are two mechanisms that can explain the moisture dependence of graphene-based materials. (i) Water molecules easily bind to the oxygen-side groups in the graphene structure via physisorption forces. Graphene essentially has a p-type conductivity, where the major charge carriers are holes. Water is an electron donor, and when it interacts with graphene, electrons pass into the graphene structure where they recombine with the holes, thus reducing their concentration. This leads to an increase in the resistance of graphene to moisture during exposure. (ii) Water is a small molecule and, especially at higher humidity levels, can intercalate between individual graphene layers in a single flake or between whole flakes. This causes an increase in the distance between the individual layers in a graphene flake or an increase in the distance between flakes, thus increasing the resistance of the entire layer [25]. These two phenomena can have a synergistic effect at high humidity values.

Humidity tests of graphene-based sensors were performed in a Vötsch $\mathrm{VCV}_{3} 7060-5$ climatic chamber. The prepared sensors were exposed to a gradual change in humidity from $20 \% \mathrm{RH}$ to $98 \% \mathrm{RH}$ (maximum limit of the climatic chamber) with a step of $10 \% \mathrm{RH}$, and then back to $20 \% \mathrm{RH}$ with the same step. The time for stabilization at every level of RH was 90 min. All humidity tests were carried out at a constant temperature of $25^{\circ} \mathrm{C}$. 
The response of the sensor to RH is shown in Figure 12. The maximum sensor response at $98 \% \mathrm{RH}$ is very high, at $98 \%$. The response value is the relative change in sensor resistance calculated according to the following Equation (1):

$$
\text { Response }=\Delta \mathrm{R} / \mathrm{R} 0=((\mathrm{R}-\mathrm{R} 0) / \mathrm{R} 0) \times 100 \%
$$

where $R(\Omega)$ is the sensor resistance during humidity exposure, and $R 0(\Omega)$ is the sensor resistance at the minimum value of humidity $\left(\mathrm{T}=25^{\circ} \mathrm{C} ; \mathrm{RH}=20 \%\right)$. The greater response at a high $\mathrm{RH}$ is probably determined by the synergy of the graphene-sensing mechanisms described above. Although there is a hysteresis between the values with an increasing and decreasing humidity, the sensor returns to the original resistance value. As the humidity decreases, the resistance value of the sensor does not return to its original value (value with rising $\mathrm{RH}$ ). This phenomenon is caused by the insufficient spontaneous desorption of water molecules from the active layer of the sensor. Especially between the individual graphene layers, water molecules are bound by a large binding energy. With a lower content of water molecules in the ambient air, spontaneous desorption improves, and the result is the same resistance value at $20 \% \mathrm{RH}$. A very good repeatability of the sensor is shown in Figure 13.

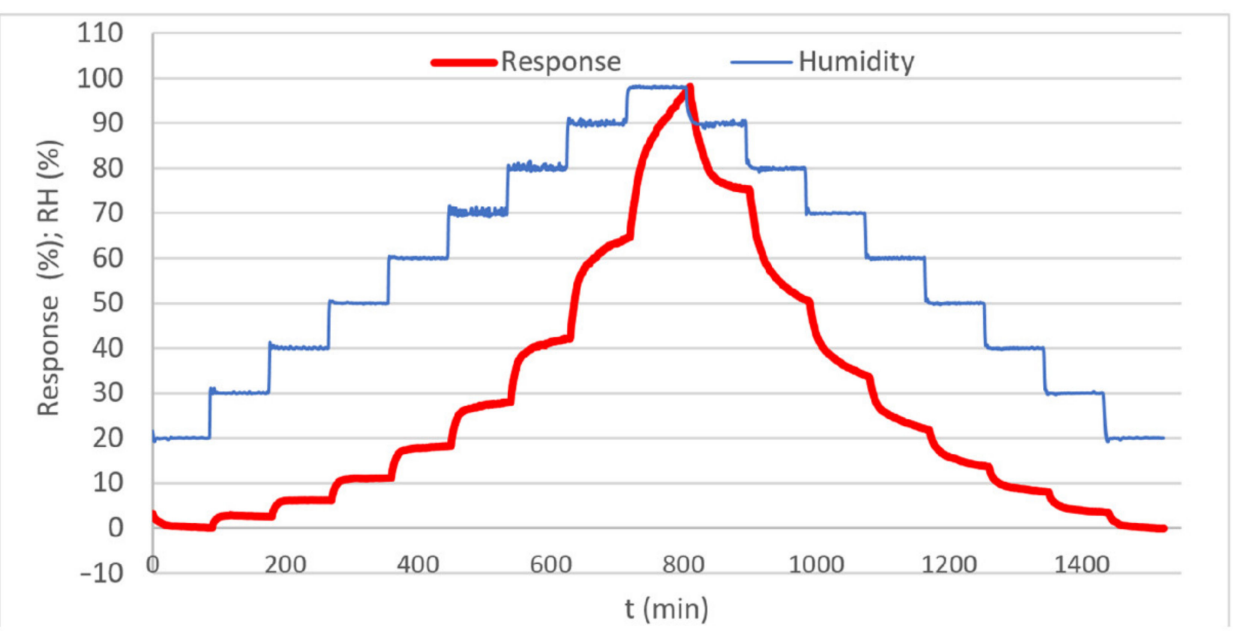

Figure 12. Response of the graphene-based, rectangle-type sensor to $\mathrm{RH}$ (condition: temperature of $\left.25{ }^{\circ} \mathrm{C}\right)$.

The prepared sensors were submitted to the same sweat test described above. The measured values were statistically analyzed, and boxplot diagrams were prepared (see Figures 14 and 15). The results show that the electrical resistance of square-type samples during aging by sweat is sufficiently stable for both sweat types. The outliers are relatively significant, but the preparation of a calibration curve for each sample makes the sample applicable, or these samples could be removed. The electrical resistance of rectangle-type samples during aging by sweat is also stable for both sweat types, with a greater variance of values, but the resistance of these samples is much higher. The changes in the resistance during testing in the chamber are also more dramatic and cause a higher sensor sensitivity. Additionally, a line chart with the median values was prepared (see Figure 16). In the case of median values, the outliers are suppressed. This chart shows that rectangle-type samples have a higher electrical resistance, but overall, the resistance of all samples is relatively stable with only a slight increase with time during sweat aging. The results also show that there is no significant difference between samples tested in alkaline and acidic sweat.

The samples after the whole aging process (i.e., $823 \mathrm{~h}$ in sweat) were submitted for observations to find visual changes (see Figure 17). The degradation of conductive lines is clearly visible, with a higher intensity for samples aged in acidic sweat. However, encapsulation clearly fulfilled its purpose, and the joint under encapsulation was protected against sweat. 


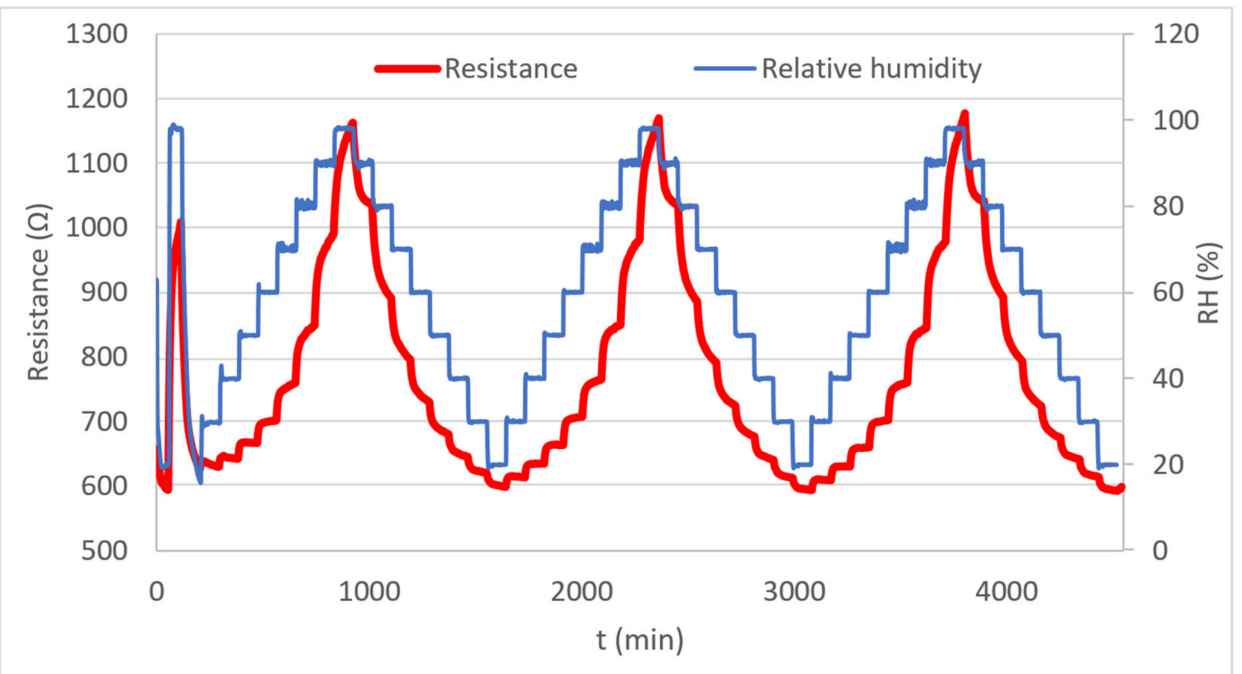

Figure 13. Repeatability of the graphene-based, rectangle-type sensor exposed to three identical humidity cycles.

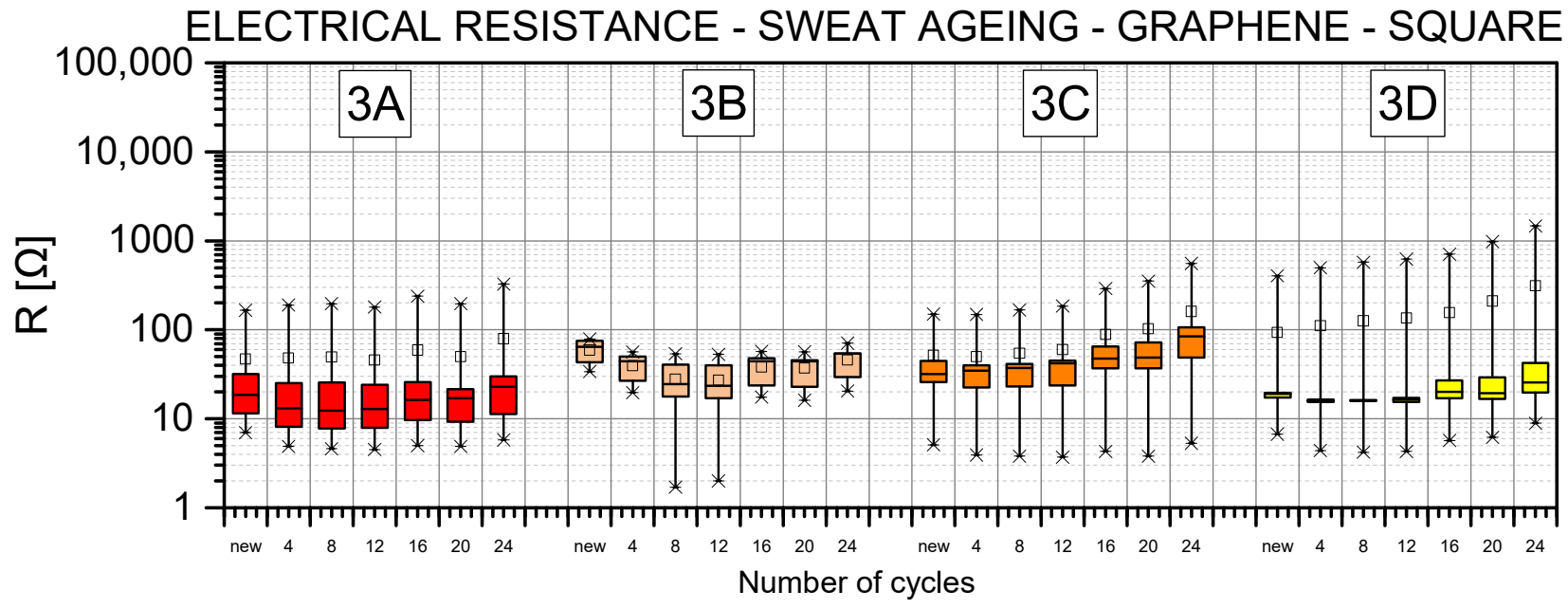

Figure 14. Boxplot diagram of graphene sensor (third sample type-square shape) electrical resistance for samples 3A, 3B, 3C and 3D.

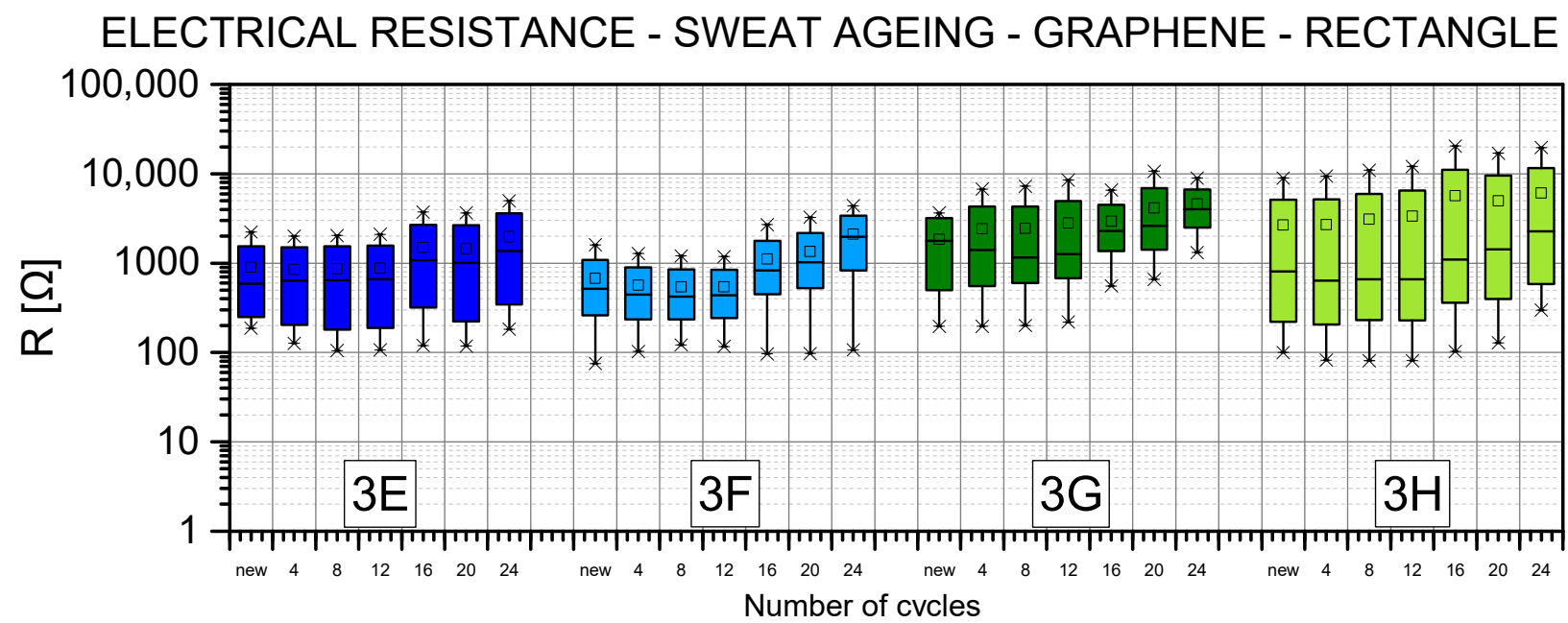

Figure 15. Boxplot diagram of graphene sensor (third sample type-rectangle shape) electrical resistance for samples $3 \mathrm{E}, 3 \mathrm{~F}, 3 \mathrm{G}$ and $3 \mathrm{H}$. 


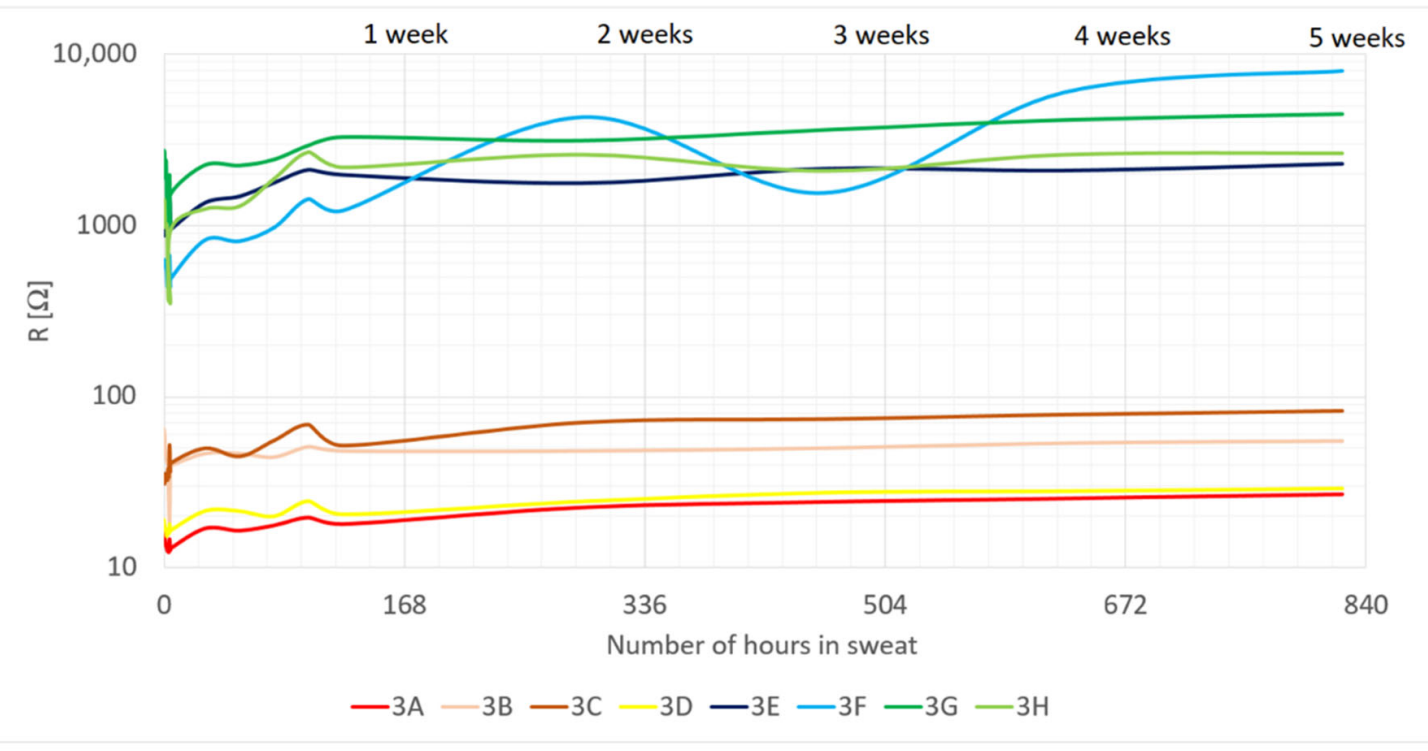

Figure 16. Medians of electrical resistance for the third sample type tested under sweat for samples $3 \mathrm{~A}, 3 \mathrm{~B}, 3 \mathrm{C}, 3 \mathrm{D}, 3 \mathrm{E}, 3 \mathrm{~F}, 3 \mathrm{G}$ and $3 \mathrm{H}$.

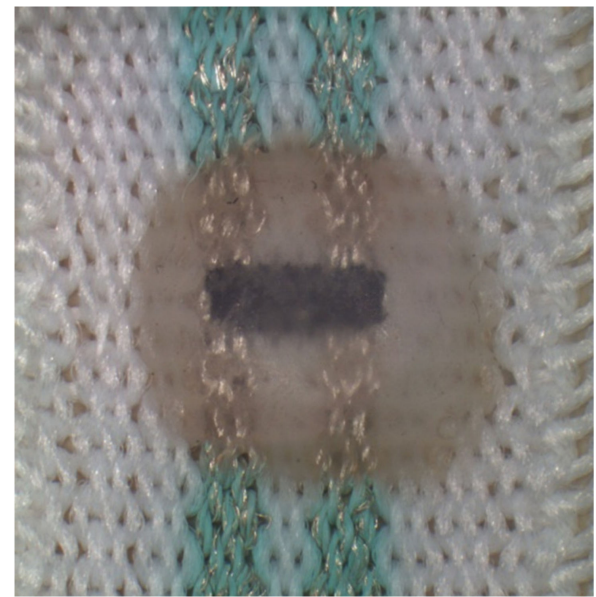

(a)

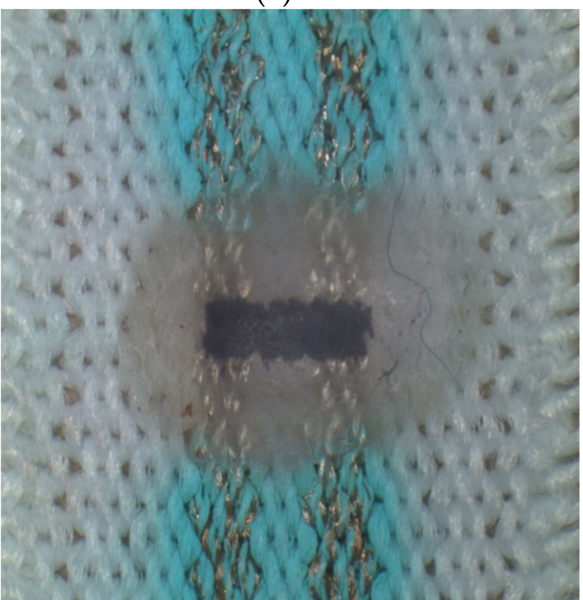

(c)

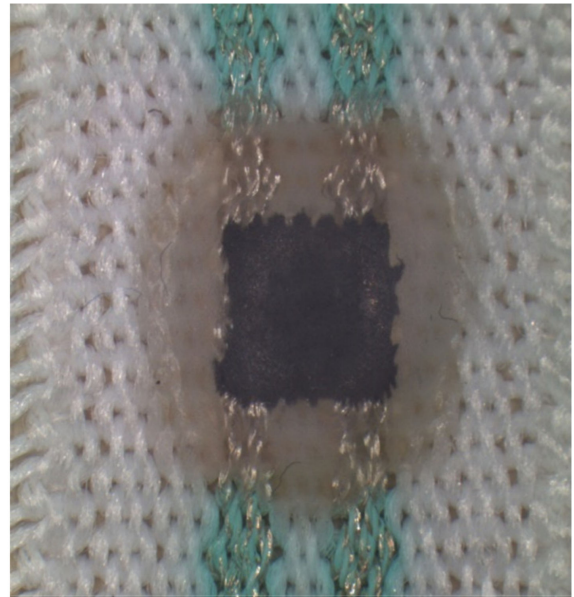

(b)

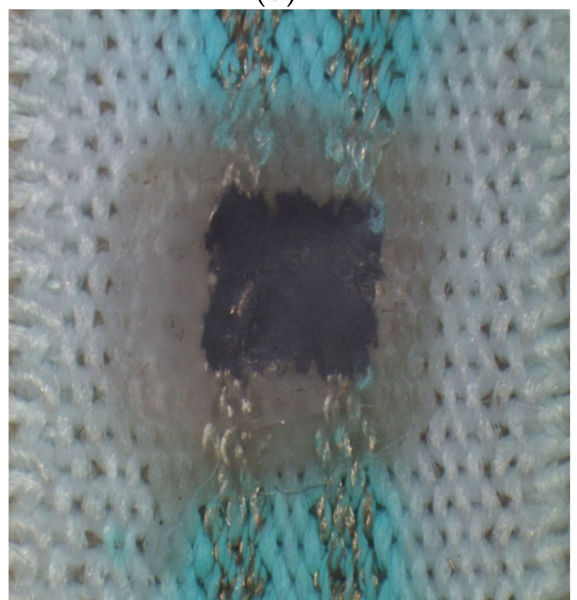

(d)

Figure 17. Example of graphene sensor samples after aging by artificial sweat (alkaline- $(\mathbf{a}, \mathbf{b})$; acidic-(c,d)). 


\section{Conclusions}

The results of the electrical resistance of adhesive-bonded or soldered joints of SMD components on conductive textile ribbons with hybrid threads after aging by artificial sweat show that both of these methods are applicable. The first hypothesis was that the electrical resistance of the adhesive-bonded or soldered joint, between the SMD component metallization and conductive track woven in the ribbons, will be reliable during accelerated aging by artificial sweat. This was fully confirmed for soldered samples and partially confirmed for glued samples. The second hypothesis was that the stretching of the ribbon at $150 \%$ of its relaxed length during the soldering or adhesive-bonding process could improve the sample reliability during aging. This was not confirmed because both sample types had similar results without significant changes. We suppose that prestretching the ribbon would have an effect on stretching tests or tests that combine stretching with sweat (i.e., more realistic conditions). The soldered samples have lower and more stable results during the whole-tested aging by both types of artificial sweat and can be fully recommended from this view. The adhesive-bonded samples have worse and slightly increasing results, but the values are still usable for some applications (e.g., passive safety illumination by SMD LED components). Both tested technologies have some pros and cons, and both technologies are usable for dedicated applications. Soldering is faster, the electrical resistance is lower, and the contact is more stable; however, soldered joints are harder and more brittle than adhesive-bonded joints. Additionally, the high thermal load during soldering can disrupt the ribbon. Adhesive bonding is slightly slower, the electrical resistance is higher, and the results are worse; however, adhesive-bonded joints are more flexible and can be gently applied to the ribbon at room temperature. Adhesive bonding can also be more suitable for components with multiple leads because conductive bridges between leads are excluded.

The results of fully printed graphene humidity sensors on conductive textile ribbons with hybrid threads show that the realization of this sensor type is possible. The results also show that the rate of humidity change measured by these sensors is in the high tens of minutes. This phenomenon is likely caused by the partial encapsulation of samples, but the intended use of these samples is to detect changes in the moisture of the human body. In this case, the temperature is relatively stable, at approximately $35-37{ }^{\circ} \mathrm{C}$, and the change in humidity does not need to be immediately detected. Thus, the measured response characteristics are sufficient for this purpose. The third hypothesis, that fully printed and partially encapsulated humidity sensors on the ribbons will be reliable during accelerated aging by artificial sweat, was confirmed.

Author Contributions: Conceptualization, M.H., J.N. and J.S.; sample preparation, M.H. and J.N.; testing, M.R., M.H. and J.S.; writing-original draft preparation, M.H. and J.S.; writing-review and editing, J.N., M.H. and J.S.; design of ribbons, R.S. All authors have read and agreed to the published version of the manuscript.

Funding: The research was supported by the European Regional Development Fund, OP RDE; Project: "Carbon allotropes with rationalized nanointerfaces and nanolinks for environmental and biomedical applications" (No. CZ.02.1.01/0.0/0.0/16_026/0008382). This research was also supported by the Student Grant Agency of the University of West Bohemia in Pilsen, grant No. SGS-2021-003 “Materials, technologies and diagnostics in electrical engineering".

Institutional Review Board Statement: Not applicable.

Informed Consent Statement: Not applicable.

Data Availability Statement: Not applicable.

Conflicts of Interest: The authors declare no conflict of interest. 


\section{References}

1. Hughes-Riley, T.; Dias, T.; Cork, C. A Historical Review of the Development of Electronic Textiles. Fibers 2018, 6, 34. [CrossRef]

2. Reddy, B.S.; Darimireddy, N.; Park, C.-W.; Chehri, A. Performance of Reconfigurable Antenna Fabricated on Flexible and Nonflexible Materials for Band Switching Applications. Energies 2021, 14, 2553. [CrossRef]

3. Mecnika, V.; Hoerr, M.; Krievins, I.; Schwarz, A. Smart Textiles for Medicine and Healthcare. In Rural Environment. Education Personality. (REEP), Proceedings of the International Scientific Conference (Latvia), Latvia University of Agriculture, Riga, Latvia, 10-11 April 2014; Latvia University of Agriculture: Jelgava, Latvia, 2017; pp. 150-161.

4. Zulan, L.; Zhi, L.; Lan, C.; Sihao, C.; Dayang, W.; Fangyin, D. Reduced Graphene Oxide Coated Silk Fabrics with Conductive Property for Wearable Electronic Textiles Application. Adv. Electron. Mater. 2019, 5, 1800648. [CrossRef]

5. Liu, S.; Tong, J.; Yang, C.; Li, L. Smart E-textile: Resistance properties of conductive knitted fabric-Single pique. Text. Res. J. 2016, 87, 1669-1684. [CrossRef]

6. Hirman, M.; Navratil, J.; Steiner, F.; Hamacek, A. Effect of Washing Cycles on Glued Conductive Joints Used on Stretchable Smart Textile Ribbons. In Proceedings of the 2020 IEEE 8th Electronics System-Integration Technology Conference (ESTC), Virtual, 15-18 September 2020; pp. 1-4.

7. Xu, B.; Eike, R.J.; Cliett, A.; Ni, L.; Cloud, R.; Li, Y. Durability testing of electronic textile surface resistivity and textile antenna performance. Text. Res. J. 2018, 89, 3708-3721. [CrossRef]

8. Liu, W.; Shangguan, D.; Lee, J.C. Evaluation of Launderability of Electrically Conductive Fabrics for E-Textile Applications. IEEE Trans. Compon. Packag. Manuf. Technol. 2020, 10, 763-769. [CrossRef]

9. Lee, J.C.; Liu, W.; Lo, C.; Chen, C.-C. Laundering Reliability of Electrically Conductive Fabrics for E-Textile Applications. In Proceedings of the 2019 IEEE 69th Electronic Components and Technology Conference (ECTC), Las Vegas, NV, USA, 28-31 May 2019; pp. $1826-1832$.

10. Hirman, M.; Navratil, J.; Steiner, F.; Hamacek, A. Electrical Resistance of Solder Joints on Conductive Ribbons. In Proceedings of the 2020 43rd International Spring Seminar on Electronics Technology (ISSE), Demanovska Valley, Slovakia, 14-15 May 2020; pp. 1-5.

11. Hirman, M.; Navratil, J.; Steiner, F.; Hamacek, A. Comparison of Conductive Ribbons Reliability during Electrical Current Ageing. In Proceedings of the 2020 International Conference on Diagnostics in Electrical Engineering, Diagnostika, Pilsen, Czech Republic, 1-4 September 2020.

12. Molla, M.T.I.; Goodman, S.; Schleif, N.; Berglund, M.E.; Zacharias, C.; Compton, C.; Dunne, L.E. Surface-mount manufacturing for e-textile circuits. In Proceedings of the 2017 ACM International Symposium on Wearable Computers-ISWC '17, Maui, HI, USA, 11-15 September 2017; pp. 18-25.

13. Kallmayer, C.; Pisarek, R.; Neudeck, A.; Cichos, S.; Gimpel, S.; Aschenbrenner, R.; Reichlt, H. New assembly technologies for textile transponder systems. In Proceedings of the 53rd Electronic Components and Technology Conference, New Orleans, LA, USA, 27-30 May 2003; pp. 1123-1126.

14. Hirman, M.; Navratil, J.; Steiner, F.; Dzugan, T.; Hamacek, A. Alternative technology for SMD components connection by non-conductive adhesive on a flexible substrate. J. Mater. Sci. Mater. Electron. 2019, 30, 14214-14223. [CrossRef]

15. Agcayazi, T.; Chatterjee, K.; Bozkurt, A.; Ghosh, T.K. Flexible Interconnects for Electronic Textiles. Adv. Mater. Technol. 2018, 3, 1700277. [CrossRef]

16. Stoppa, M.; Chiolerio, A. Wearable Electronics and Smart Textiles: A Critical Review. Sensors 2014, 14, 11957-11992. [CrossRef] [PubMed]

17. Choi, J.-Y.; Oh, T.S. Contact Resistance Comparison of Flip-Chip Joints Produced with Anisotropic Conductive Adhesive and Nonconductive Adhesive for Smart Textile Applications. Mater. Trans. 2015, 56, 1711-1718. [CrossRef]

18. Sehrawat, P.; Abid; Islam, S.S.; Mishra, P. Reduced graphene oxide based temperature sensor: Extraordinary performance governed by lattice dynamics assisted carrier transport. Sens. Actuators B Chem. 2018, 258, 424-435. [CrossRef]

19. Lv, C.; Hu, C.; Luo, J.; Liu, S.; Qiao, Y.; Zhang, Z.; Song, J.; Shi, Y.; Cai, J.; Watanabe, A. Recent Advances in Graphene-Based Humidity Sensors. Nanomaterials 2019, 9, 422. [CrossRef] [PubMed]

20. Sahatiya, P.; Puttapati, S.K.; Srikanth, V.V.S.S.; Badhulika, S. Graphene-based wearable temperature sensor and infrared photodetector on a flexible polyimide substrate. Flex. Print. Electron. 2016, 1, 1-9. [CrossRef]

21. Kong, D.; Le, L.T.; Li, Y.; Zunino, J.L.; Lee, W. Temperature-Dependent Electrical Properties of Graphene Inkjet-Printed on Flexible Materials. Langmuir 2012, 28, 13467-13472. [CrossRef] [PubMed]

22. NeVo GmbH, Lead-Free Solder Paste SnBi PF602-Safety Data Sheet. Available online: https://www.nevo-solder.com/wpcontent/uploads/Solder-Paste-Lead-Free-SnBi-SDS-V02-EN.pdf (accessed on 30 October 2021).

23. Henkel, Henkel Loctite AA 3926 Safety Data Sheet. 2018. Available online: https://www.henkel-adhesives.com/us/en/product/ uv-curing-adhesives/loctite_aa_3926.html (accessed on 15 November 2021).

24. International Organization for Standardization. ISO105-E04 Textiles-Tests for Colour Fastness-Part E04: Colour Fastness to Perspiration. Geneva, Switzerland, 2013.

25. Liang, R.; Luo, A.; Zhang, Z.; Li, Z.; Han, C.; Wu, W. Research Progress of Graphene-Based Flexible Humidity Sensor. Sensors 2020, 20, 5601. [CrossRef] [PubMed] 